\title{
Relationship between Sodium Intake and Water Intake: The False and the True
}

\author{
Lise Bankir ${ }^{a} b \quad$ Julie Perucca ${ }^{a} b \quad$ Peter Norsk ${ }^{c}$ Nadine Bouby ${ }^{a, b}$ \\ Morten Damgaard ${ }^{d}$
}

aINSERM Unit 1138, Centre de Recherche des Cordeliers, Paris, France; ${ }^{b}$ Université Pierre et Marie Curie, Paris, France; 'Baylor College of Medicine, Center for Space Medicine, Houston, TX, USA; ${ }^{\mathrm{d} C e n t r e ~ o f ~ F u n c t i o n a l ~}$ Imaging and Research, Department of Clinical Physiology and Nuclear Medicine, Hvidovre Hospital, University of Copenhagen, Copenhagen, Denmark

\section{Keywords}

Urine volume - Vasopressin · Body weight · Potassium .

Urea. Water

\begin{abstract}
Background: Generally, eating salty food items increases thirst. Thirst is also stimulated by the experimental infusion of hypertonic saline. But, in steady state, does the kidney need a higher amount of water to excrete sodium on a high than on a low sodium intake? This issue is still controversial. The purpose of this review is to provide examples of how the kidney handles water in relation to salt intake/output. It is based on re-analysis of previously published studies in which salt intake was adjusted to several different levels in the same subjects, and in databases of epidemiologic studies in populations on an ad libitum diet. Summary and Key Messages: These re-analyses allow us to draw the following conclusions: (1) In a steady state situation, the urine volume (and thus the fluid intake) remains unchanged over a large range of sodium intakes. The adaptation to a higher sodium excretion rests only on changes in urinary sodium concentration. However, above a certain limit, this concentration cannot increase further and the urine volume may then increase. (2) In population studies, it is not legitimate to assume that sodium is responsible for changes in urine volume, since people who eat more sodium also eat more of other nutrients leading to
\end{abstract}

an increase in the excretion of potassium, urea and other solutes, besides sodium. (3) After an abrupt increase in sodium intake, fluid intake is increased in the first few days, but urine volume does not change. The extra fluid drunk is responsible for an increase in body weight.

C 2017 The Author(s)

Published by S. Karger AG, Basel

\section{Introduction}

Although thirst is difficult to quantify [1], it is frequently experienced that eating more salty food than usual increases thirst. However, this concept is challenged by some authors [2]. Salt appetite and thirst are tightly coupled functions [3-5]. According to some studies, thirst is associated with carbohydrate and protein intake [6]. Thirst is also stimulated by the experimental infusion of hypertonic saline [7]. But does the kidney use this extra water to excrete the salt? In other words, is urine output increased when the extra sodium ingested is excreted? And are the fluid intake and urine output higher on a high than on a low salt intake, once subjects are in a steady

8th Hydration for Health Annual Scientific Conference (June 29, 2016), Guest Editor: Prof. Lawrence Armstrong, University of Connecticut, USA.

\section{KARGER}

E-Mail karger@karger.com www.karger.com/anm

\section{The Author(s) \\ Published by S. Karger AG, Basel \\ Karger \\ Open access}

This article is licensed under the Creative Commons AttributionNonCommercial-NoDerivatives 4.0 International License (CC BYNC-ND) (http://www.karger.com/Services/OpenAccessLicense). Usage and distribution for commercial purposes as well as any distribution of modified material requires written permission.
Lise Bankir

INSERM Unit 1138, Centre de Recherche des Cordeliers 15 rue de l'Ecole de Médecine

FR-75006 Paris (France)

E-Mail lise.bankir@inserm.fr or lise.bankir@ renalphy.com 
Table 1. Demographic data for all the cohorts used in the present report

\begin{tabular}{|c|c|c|c|c|c|c|c|c|}
\hline Study & $\mathrm{N}, \mathrm{M} / \mathrm{W}$ & Condition & $\begin{array}{l}\text { Age, years, } \\
\text { mean (range) }\end{array}$ & $\mathrm{Na}$ diets & Order & $\begin{array}{l}\text { Duration on } \\
\text { each diet, days }\end{array}$ & Location & Reference \\
\hline A & $14 \mathrm{M}$ & NT & $23(20-28)$ & LS MS HS & Random & 7 & Lausanne, Switzerland & [9] \\
\hline B & $25 \mathrm{M} / 18 \mathrm{~W}$ & HT & $42(21-61)$ & LS HS & Random & 7 & Lausanne, Switzerland & [9] \\
\hline $\mathrm{C}$ & $12 \mathrm{M}$ & $\mathrm{HT}$ & $47(30-65)$ & LS MS HS & Random & 7 & Reggio, Italy & {$[10]$} \\
\hline $\mathrm{F}$ & $12 \mathrm{M}$ & NT & $57(29-78)$ & LS HS & $\begin{array}{l}\mathrm{LS} \rightarrow \mathrm{HS} \\
\mathrm{HS} \rightarrow \mathrm{LS}\end{array}$ & 7 & Copenhagen, Denmark & {$[14]$} \\
\hline G & $24 \mathrm{M} / 13 \mathrm{~W}$ & NT & $34(21-44)$ & Free diet & - & - & Lyon, France & $\begin{array}{l}\text { A.Hadj-Aissa. } \\
\text { Personal } \\
\text { communication }\end{array}$ \\
\hline
\end{tabular}

N, number of subjects; M and W, men and women; NT and HT, normotensive and hypertensive; LS, MS and HS, low, medium and high sodium intake.

state? These issues are still controversial. The purpose of this review is to provide examples of how the kidney handles water in relation to salt intake/output in humans. It is based on re-analysis of previously published studies in which salt intake was adjusted to several different levels in the same subjects, and in databases of epidemiologic studies in populations on an ad libitum diet. Data from 3 of these studies had already been used for other re-analyses documenting gender differences in urine osmolality [8].

It is important to distinguish between (1) intervention studies in which salt intake is altered to several predefined levels during several successive periods in the same subjects, without any other change in the diet, and (2) observational studies in different subjects of a population who exhibit diverse levels of salt intake (often evaluated by sodium excretion). In the first case, one can expect an increase in salt excretion without a change in the excretion of other solutes. Whereas in the second case, the different levels of sodium intake/excretion may likely be associated with unknown differences in the consumption of other nutrients and thus unknown changes in the excretion of other solutes.

In this review, we will neither address the mechanisms involved in the regulation of sodium excretion nor discuss the influence of salt intake on blood pressure. Our purpose is only to provide easily accessible observations derived from re-analyses of previously available data.

The sodium excretion rate (often abbreviated $\mathrm{U}_{\mathrm{Na}} \mathrm{V}$ ) is the product of 2 terms, $\mathrm{U}_{\mathrm{Na}}$ and $\mathrm{V}$, where $\mathrm{U}_{\mathrm{Na}}$ is the con- centration of sodium in the urine, in $\mathrm{mmol} / \mathrm{L}$, and $\mathrm{V}$ is the urine flow rate (often called urine volume) in liter/unit time. $\mathrm{U}_{\mathrm{Na}} \mathrm{V}$ is expressed in $\mathrm{mmol} /$ unit time (whether minute, hour or day). Although $\mathrm{U}_{\mathrm{Na}} \mathrm{V}$ is reported in many papers as an estimate of sodium intake, the 2 terms $U_{\mathrm{Na}}$ and $\mathrm{V}$ that allow its calculation are rarely reported. It is interesting to see how the kidney adapts to a new level of $\mathrm{Na}$ excretion when the level of $\mathrm{Na}$ intake is changed. Are there changes in $\mathrm{U}_{\mathrm{Na}}$ or in $\mathrm{V}$, or a combination of both? And is the adaptation the same for an acute sodium load and for a chronic change, once the subjects have reached a new steady state? Below, we will display some observations that provide answers to these questions.

\section{Description of the Databases Re-Analyzed in This Study}

The data used in the analyses presented below were not collected for the purpose of this review. They originate from earlier studies in which the authors focused on other issues and did not discuss possible differences in $\mathrm{U}_{\mathrm{Na}}$ or $\mathrm{V}$ in relation to the level of sodium intake. Several authors agreed to send us their databases, thus allowing new calculations on previously collected data (see acknowledgements). Table 1 shows the main characteristics of the subjects and their diet in each study. In the data presented here, as in a number of other studies, urinary $\mathrm{Na}$ excretion is assumed to reflect closely $\mathrm{Na}$ intake. Subjects and methods 
Table 2. Urine data in men and women of the DASH-Na study on 3 different levels of sodium intake (Study E). This data concerns only the group of subjects on the control diet ( $n=191$; not on the DASH diet)

\begin{tabular}{|c|c|c|c|c|c|c|c|c|}
\hline \multirow{2}{*}{$\begin{array}{l}\mathrm{Na} \text { intake, } \\
\mathrm{mmol} / \text { day }\end{array}$} & \multicolumn{2}{|c|}{$\mathrm{Na}$ excretion, $\mathrm{mmol} /$ day } & \multicolumn{2}{|c|}{$\mathrm{U}_{\mathrm{osm}}, \mathrm{mOsm} / \mathrm{kg} \mathrm{H}_{2} \mathrm{O}$} & \multicolumn{2}{|c|}{$\mathrm{U}_{\mathrm{Na}}, \mathrm{mmol} / \mathrm{L}$} & \multicolumn{2}{|c|}{ Urine volume, L/day } \\
\hline & men & women & men & women & men & women & men & women \\
\hline Low (50) & $67 \pm 4$ & $62 \pm 4$ & $495 \pm 26$ & $442 \pm 20$ & $53 \pm 4$ & $53 \pm 4$ & $1.63 \pm 0.10$ & $1.39 \pm 0.07$ \\
\hline Medium (100) & $118 \pm 5$ & $95 \pm 4$ & $551 \pm 26$ & $464 \pm 20$ & $90 \pm 5$ & $76 \pm 4$ & $1.63 \pm 0.10$ & $1.47 \pm 0.08$ \\
\hline High (150) & $159 \pm 5$ & $126 \pm 5$ & $543 \pm 22$ & $499 \pm 24$ & $109 \pm 5$ & $100 \pm 5$ & $1.72 \pm 0.10$ & $1.47 \pm 0.06$ \\
\hline High/low & 2.37 & 2.03 & 1.10 & 1.13 & 2.06 & 1.89 & 1.06 & 1.06 \\
\hline
\end{tabular}

$n=88$ men and 103 women. Mean \pm SEM of 24 -h urine data obtained in the same subjects after 1 month on each level of Na intake, in random order. Reproduced from [8] with minor modification.

will be described only very briefly in each section because this information is available in previous publications. All results shown are based on 24-h urine collections (except for the results of the acute sodium loading). Importantly, we want to stress that water intake was ad libitum in all the studies presented here, even when sodium intake was altered. Subjects were not given any recommendations regarding the quantity of water or fluid they should drink.

\section{$\mathrm{U}_{\mathrm{Na}}$ and $\mathrm{V}$ During Different Sodium Intakes in Chronic Conditions}

Figure 1 illustrates $\mathrm{Na}$ excretion, $\mathrm{U}_{\mathrm{Na}}$ and $\mathrm{V}$ in $24-\mathrm{h}$ urine from 4 different groups of subjects (studies A to D in Table 1) [9-11] who were studied sequentially, while on different levels of salt intake in random order (except in one case). Only salt intake was reduced or increased, while the subjects continued to eat their usual diet or a diet prepared by the research center. It appears clearly that in all studies (from France, Switzerland and Italy), the adaptation to variable $\mathrm{Na}$ excretion was achieved exclusively by corresponding changes in $U_{\mathrm{Na}}$ without any change in V. This is true in normotensive subjects as well as in hypertensive subjects.

Another example of the lack of change in $\mathrm{V}$ in the face of significant changes in salt intake is provided by the DASH-Na study (study E) [12]. When challenged with different salt intakes in random order, amounting to 50, 100 or $150 \mathrm{mmol} /$ day, for $1 \mathrm{month}$ each, the kidney adapted exclusively by changes in $\mathrm{U}_{\mathrm{Na}}$ (doubling between the lowest and highest levels) with only a negligible change in $\mathrm{V}(+6 \%)$, as shown in Table 2 for men and women separately. Table 3 shows the results of another study in which sodium intake was varied even more widely in the same subjects on successive 7-day periods in random order to values of 20,200, or

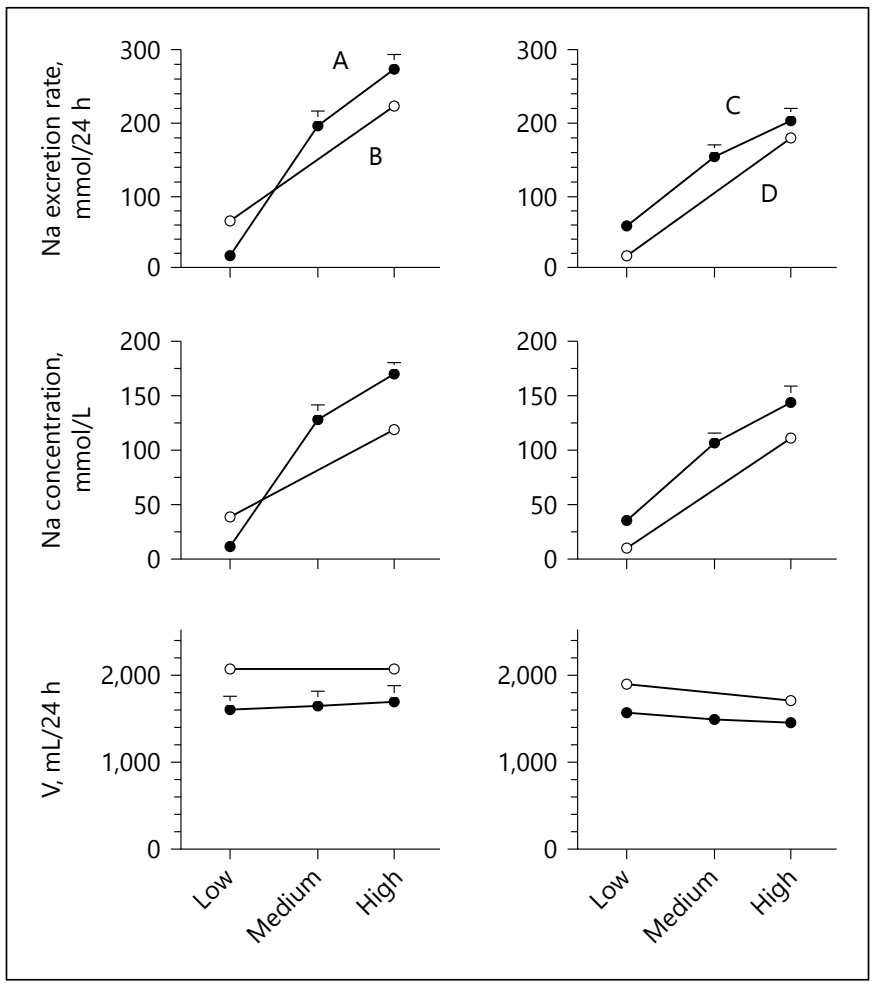

Fig. 1. Sodium excretion rate, the concentration of sodium in the urine $\left(\mathrm{U}_{\mathrm{Na}}\right)$ and urine flow rate $(\mathrm{V})$ while consuming different levels of sodium in 3 studies from Switzerland (A, B), Italy (C) and France (D). A = healthy subjects, B, C and D = hypertensive subjects. In each of these groups, the adaptation to the different levels of sodium intake was achieved by increases in $\mathrm{U}_{\mathrm{Na}}$ without any change in $\mathrm{V}$.

$400 \mathrm{mmol} /$ day [13]. Even with these very wide differences, daily urine volume was similar during all levels of $\mathrm{Na}$ intake, and the kidney adapted only by marked changes in $\mathrm{U}_{\mathrm{Na}}$.

Significant differences in salt intake with no difference in urine output are also observed in the absence of any 
Table 3. Urine data of 24 men (19-32 years of age) who consumed 3 different levels of sodium intake

\begin{tabular}{lcccc}
\hline Na intake, mmol/day & Na excretion rate, mmol/day & $\mathrm{U}_{\mathrm{osm}}, \mathrm{mOsm} / \mathrm{kg} \mathrm{H}_{2} \mathrm{O}$ & $\mathrm{U}_{\mathrm{Na}}, \mathrm{mmol} / \mathrm{L}$ & Urine volume, L/day \\
\hline Low (10) & $21 \pm 3$ & $326 \pm 38$ & $11 \pm 1$ & $2.12 \pm 0.25$ \\
Medium (200) & $182 \pm 8$ & $482 \pm 52$ & $101 \pm 8$ & $2.23 \pm 0.28$ \\
High (400) & $339 \pm 12$ & $565 \pm 48$ & $162 \pm 11$ & $2.30 \pm 0.16$ \\
High/low & 16.1 & 1.73 & 14.7 & 1.08 \\
\hline
\end{tabular}

Mean \pm SEM of 24-h urine data obtained in the same subjects during the last 3 days of a 7 day-period on each level of Na intake in random order. Adapted from data shown in Table 1 of [13].

Table 4. Sodium, protein intake and urine volume in a sample of 1,339 subjects of the Swiss population, divided into 3 categories according to their BMI

\begin{tabular}{llllll}
\hline & BMI, kg/m & $n$ & Estimated Na intake, g/24h & Estimated protein intake, g/24h & Urine volume, mL/24 h \\
\hline Lean & $<25$ & 691 & $3.1(2.3-4.2)$ & $69.7(57.0-82.5)$ & $1,862(1,249-2,510)$ \\
Overweight & $\geq 25$ to $<30$ & 448 & $3.7(2.7-4.9)$ & $79.1(66.3-98.7)$ & $1,876(1,312-2,400)$ \\
Obese & $\geq 30$ & 200 & $4.2(2.9-5.8)$ & $92.1(73.7-111.7)$ & $1,851(1,360-2,388)$ \\
Obese/lean & & & 1.35 & 1.32 & 0.99 \\
$p$ value & & & $<0.001$ & $<0.001$ & NS \\
\hline
\end{tabular}

Median (interquartile range).

Estimated $\mathrm{Na}$ and protein intake were calculated based on the $24 \mathrm{~h}$ urinary excretion of $\mathrm{Na}$ and urea nitrogen respectively. The numerical values presented here are copied from data shown in Tables 1 and 2 of the study of Ogna et al [14]. $p$ values are from a nonparametric test for trend across BMI categories. NS, non significant.

intervention. In a study of a sample of the Swiss population $(n=1,339)$, subjects were divided into 3 categories according to their body mass index (lean, overweight, obese) [14]. The results published in this original paper show that the estimated salt intake rose significantly from one category to the next as shown in Table 4. Estimated protein intake also increased across categories in the same proportion as did salt intake. But interestingly, the urine output was exactly the same in the 3 categories of subjects [14]. This illustrates that the daily urine output is independent of the salt and protein intake in a population.

\section{$\mathrm{U}_{\mathrm{Na}}$ and $\mathrm{V}$ after an Abrupt Change in Sodium Intake}

In a previous study, Damgaard et al. [15] addressed the adaptation of sodium excretion after an abrupt change in salt intake in both directions. Twelve healthy male subjects were submitted in a randomized order to 2 levels of salt intake (70 and $250 \mathrm{mmol} /$ day; study F). Fluid intake was ad libitum. Their article showed how daily sodium excretion $\left(\mathrm{U}_{\mathrm{Na}} \mathrm{V}\right)$ adapted, day after day, to these abrupt switches in salt intake [15], but $\mathrm{U}_{\mathrm{Na}}$ and $\mathrm{V}$ were not reported.
Figure 2 shows these 2 variables along with the previously published $\mathrm{U}_{\mathrm{Na}} \mathrm{V}$. It appears clearly that $\mathrm{V}$ remained fairly constant over the whole period of observation in spite of marked changes in sodium excretion. The kidney adapted to these changes in sodium excretion only by changing $\mathrm{U}_{\mathrm{Na}}$, without any change in urine output. Although the changes in salt intake were abrupt, the increase in $\mathrm{U}_{\mathrm{Na}}$ and in sodium excretion required 2-3 days to reach a new plateau, thus showing the well-described lag in reaching a new steady state after abrupt changes in sodium intake, and the positive or negative balance that results from this lag. Body weight was $1.2 \pm 0.2 \%(p<0.005)$ higher on the high than on the low Na intake. Similar observations (stable urine flow rate and rise in $\mathrm{U}_{\mathrm{Na}}$ ) were observed in another study performed by the same group in younger subjects [16].

\section{$\mathrm{U}_{\mathrm{Na}}$ and $\mathrm{V}$ in Different Individuals Consuming an ad libitum Diet}

The results shown in the previous 2 sections show without doubt that daily urine volume does not change when sodium intake/excretion is altered in either direc- 


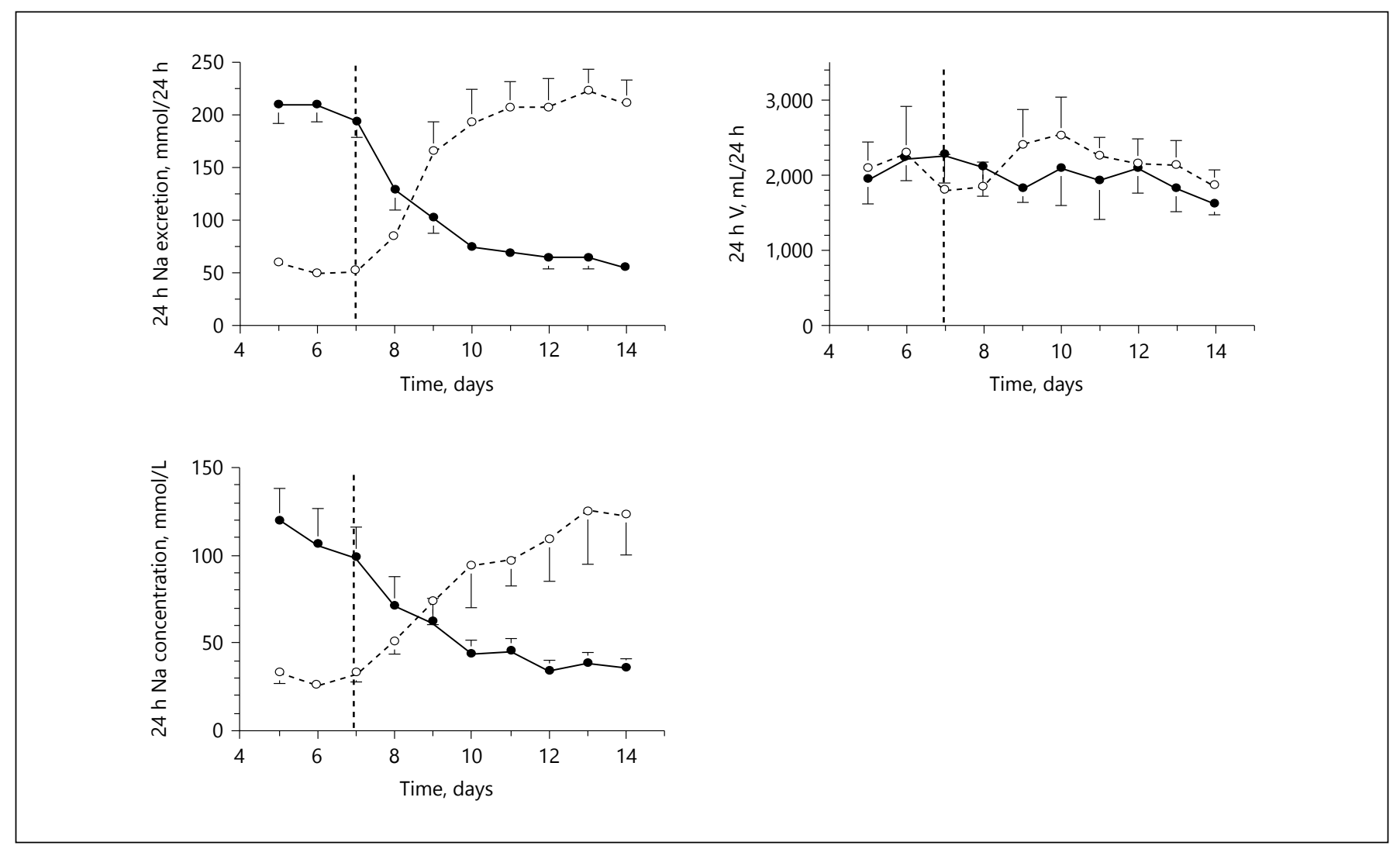

Fig. 2. Sodium excretion rate, urine sodium concentration $\left(\mathrm{U}_{\mathrm{Na}}\right)$ and urine flow rate $(\mathrm{V})$ of 12 subjects submitted to low and to high sodium intakes (70 and $250 \mathrm{mmol} /$ day, respectively) for 1 week each, in random order, with an abrupt change of $\mathrm{Na}$ intake (Study F): from low to high (open circles) and from high to low (closed circles). In each direction, a new steady state was reached after 2-3 days, and the adaptation to the new level of salt intake was achieved by increases of $U_{\mathrm{Na}}$ with negligible change of V. Mean \pm SEM. Some error lines are too small to be visible. tion in the same subjects, without any other change in the diet. However, the situation may be different when considering the relationship between daily sodium excretion and urine volume in transversal epidemiologic population studies. Some studies have reported that urine volume increases in parallel with sodium excretion [17]. This is the case in the data shown in Figure 3, top panel. A 24-h urine collection was performed in healthy subjects in which the renal function was evaluated for diverse clinical investigations or for potential kidney donation (study G). It shows that the difference in sodium excretion among subjects depends on differences in both $\mathrm{U}_{\mathrm{Na}}$ and $\mathrm{V}$. But, although often neglected in many studies, it is important to stress that not only does sodium excretion vary between subjects, the excretion of other main urinary solutes also varies significantly (e.g., 37 and 38\% increase between tertiles 3 and 1 for potassium and urea, respectively). Sodium represented only 15 (in T1) to $20 \%$ (in T3) of all urinary solutes. Thus, it is not legitimate to assume that the $55 \%$ higher water excretion in tertile 3 than in tertile $1(2.24 \pm 0.20$ vs. $1.55 \pm 0.18 \mathrm{~L} /$ day $)$ is due to the higher sodium excretion. Figure 3, bottom panel, illustrates this relationship in a group of 117 subjects, a subgroup issued from the SU.VI.MAX cohort [18] in which a 24-h urine collection was performed (study $\mathrm{H}$ ). The 24-h excretions of potassium and urea are plotted as a function of the 24 -h excretion of sodium. This figure shows that people who eat/excrete more sodium are actually eating more of other nutrients that also generate osmoles excreted in the urine. In this study, sodium represents on the average $18.4 \pm 3.2 \%$ of all urinary osmoles. Altogether, these observations show that, in subjects on an ad libitum diet, the influence of sodium cannot be dissociated from that of other urinary solutes (and thus other nutrients) while attempting to evaluate its possible influence on urine output. 
Fig. 3. a Sodium excretion rate, urine sodium concentration $\left(\mathrm{U}_{\mathrm{Na}}\right)$ and urine flow rate $(\mathrm{V})$ in 37 healthy subjects (Study $\mathrm{G}$ ) divided into tertiles (T1 to T3) according to their daily sodium excretion. With higher sodium excretion rate, both $\mathrm{U}_{\mathrm{Na}}$ and $\mathrm{V}$ are higher. b Daily potassium (filled circles) and urea (open circles) excretion rates plotted as a function of daily sodium excretion rate in 117 subjects of the French population (Study H). Potassium and urea excretions exhibit a positive relationship with sodium excretion. The regression lines are $\mathrm{K}$ excretion $=0.15 \mathrm{Na}$ excretion +31.02 $(r=0.485, p<0.001)$ and urea excretion $=$ $1.25 \mathrm{Na}$ excretion $+155(r=0.655, p<$ $0.001)$.

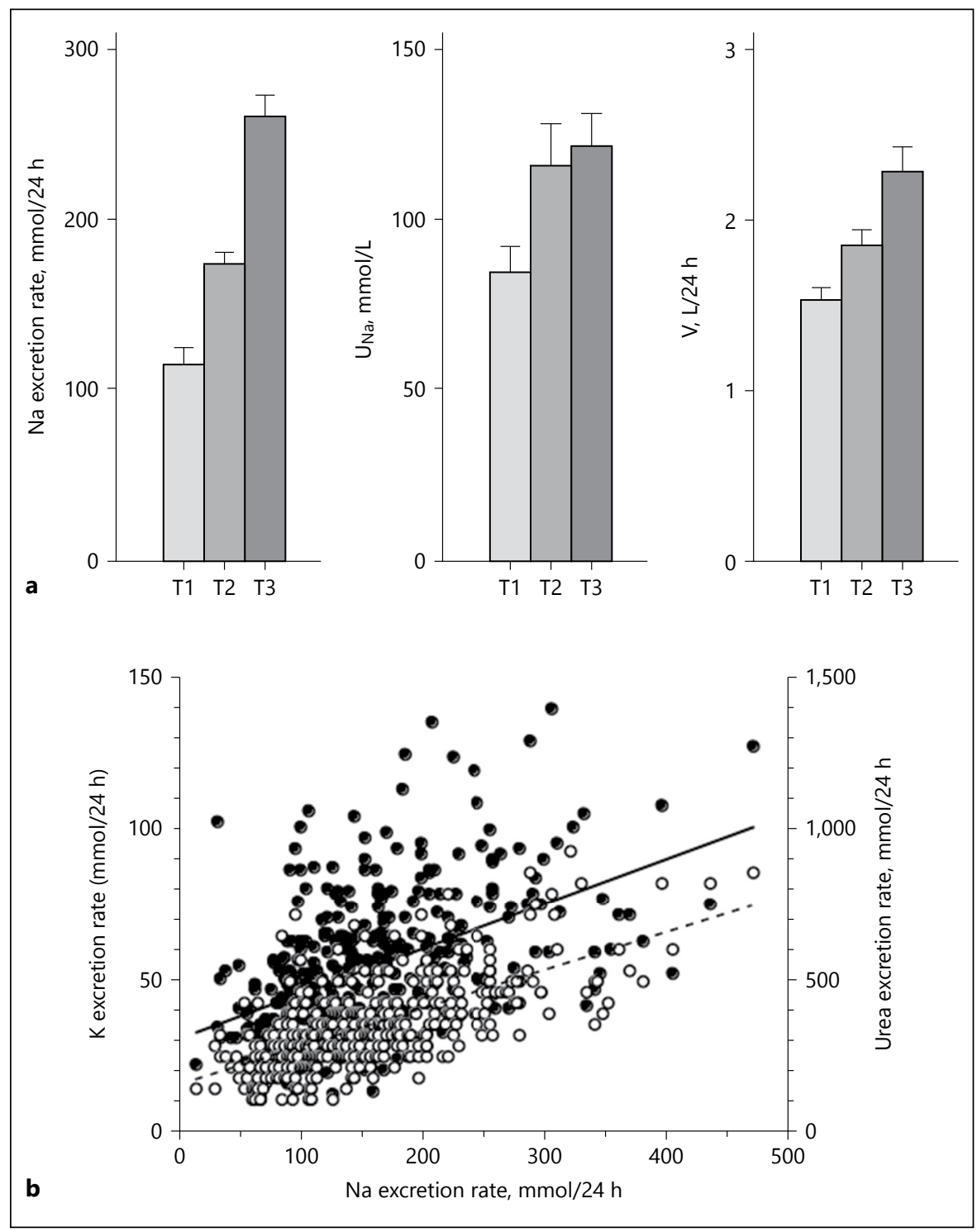

\section{$\mathrm{U}_{\mathrm{Na}}$ and $\mathrm{V}$ in Different Populations throughout the World}

The Intersalt study evaluated the relationship between blood pressure and sodium intake (evaluated by 24 -h urinary sodium excretion) in 52 populations throughout the World [19]. Twenty-four hour urine samples were obtained for 200 subjects in each population on their normal diet ( 25 subjects of each gender in 4 different age groups). In the initial report, a table provided the mean 24 -h sodium and potassium excretions and 24-h urine volume for each population (Appendix II in [19]). Daily sodium excretion in these populations varied over a wide range from 1 to $246 \mathrm{mmol} / 24 \mathrm{~h}$. These data allowed us to recalculate the mean urine sodium and potassium concentrations for each population. Table 5 shows the mean of urine data for the 52 populations divided into 4 quartiles of 13 populations each, according to increasing 24-h sodium excretion. These results show that 24-h K excretion and urine K concentration are almost identical among population quartiles. Twenty-four hour urine volume is also quite similar, with mean values in the $1.3-1.5 \mathrm{~L} / 24 \mathrm{~h}$ range. The wide differences in $\mathrm{Na}$ excretion across quartiles are accounted for only by differences in the concentration of sodium in urine. At the 2 extremes of the Intersalt study are 3 populations living in the tropical rain forest and 3 populations living in Far East Asia, respectively. In these 2 extreme subgroups, very low $\mathrm{Na}$ intake ( $\mathrm{Na}$ excretion rate below 
Table 5. Urine data in the 52 different populations from the "Intersalt" study, organized according to increasing 24 h sodium excretion and divided into quartiles

\begin{tabular}{|c|c|c|c|c|c|c|c|}
\hline & $\begin{array}{l}\mathrm{Na} \text { excretion } \\
\mathrm{mmol} / 24 \mathrm{~h}\end{array}$ & $\begin{array}{l}\text { Range } \mathrm{Na} \text { excretion } \\
\mathrm{mmol} / 24 \mathrm{~h}\end{array}$ & $\begin{array}{l}\text { K excretion } \\
\mathrm{mmol} / 24 \mathrm{~h}\end{array}$ & $\begin{array}{l}\text { Urine volume, } \\
\mathrm{L} / 24 \mathrm{~h}\end{array}$ & $\begin{array}{l}\text { Range urine } \\
\text { volume, } \mathrm{L} / 24 \mathrm{~h}\end{array}$ & $\begin{array}{l}\mathrm{U}_{\mathrm{Na}} \\
\mathrm{mmol} / \mathrm{L}\end{array}$ & $\begin{array}{l}\mathrm{U}_{\mathrm{K}}, \\
\mathrm{mmol} / \mathrm{L}\end{array}$ \\
\hline Q $1(n=13)$ & $100 \pm 15$ & $1-141$ & $54 \pm 5$ & $1.30 \pm 0.10$ & $0.65-1.74$ & $78 \pm 11$ & $45 \pm 6$ \\
\hline Q $2(n=13)$ & $150 \pm 1$ & $141-156$ & $55 \pm 4$ & $1.48 \pm 0.07$ & $1.13-2.01$ & $103 \pm 4$ & $38 \pm 2$ \\
\hline Q $3(n=13)$ & $170 \pm 2$ & $161-180$ & $58 \pm 4$ & $1.29 \pm 0.06$ & $1.02-1.67$ & $135 \pm 6$ & $45 \pm 3$ \\
\hline $\mathrm{Q} 4(n=13)$ & $200 \pm 5$ & $181-246$ & $53 \pm 3$ & $1.44 \pm 0.06$ & $1.13-1.79$ & $142 \pm 5$ & $38 \pm 3$ \\
\hline
\end{tabular}

Mean \pm SEM.

24-h $\mathrm{Na}$ and $\mathrm{K}$ excretion, as well as $\mathrm{V}$ are calculated from data shown in Appendix II in the Intersalt study report [18].

In each of the 52 countries, $\mathrm{U}_{\mathrm{Na}}$ and $\mathrm{U}_{\mathrm{K}}$ were recalculated as $\mathrm{U}_{\mathrm{Na}} \mathrm{V}$ or $\mathrm{U}_{\mathrm{K}} \mathrm{V}$ divided by $\mathrm{V}$. The 52 populations were then divided into quartiles of increasing sodium excretion and data averaged in each quartile.

In quartile 1 , the SEM of $\mathrm{Na}$ excretion is very large because 4 populations showed very low values of $0.9,12,37$, and $57 \mathrm{mmol} / 24 \mathrm{~h}$. Urine volume in these 4 populations was $1.07,1.58,0.65$, and $1.07 \mathrm{~L} / 24 \mathrm{~h}$ respectively.

$50 \mathrm{mmol} / 24 \mathrm{~h}$ ) is associated with a mean $\mathrm{V}$ of $1.09 \mathrm{~L} / 24 \mathrm{~h}$, whereas very high $\mathrm{Na}$ intake (excretion rate above $204 \mathrm{mmol} / 24 \mathrm{~h}$ ) is associated with a mean V of $1.49 \mathrm{~L} / 24 \mathrm{~h}$. The mean potassium excretion rate in these 2 small subgroups was 73 and $44 \mathrm{mmol} / 24 \mathrm{~h}$, respectively. This reevaluation of previously published data of the Intersalt study show, for the first time to our knowledge, that the mean daily urine volume in diverse populations is fairly similar throughout the World and independent of the level of sodium intake (when evaluated on representative groups of 200 subjects per population). Only extremely low intakes (below $50 \mathrm{mmol} / 24 \mathrm{~h}$ ), uncommon in most countries, may be associated with slightly lower urine output.

In another investigation the mean urinary sodium excretion and volume of 24-h urine are reported in a study of the role of genetic factors in hypertension, involving several hundred subjects per country in 6 different European countries [20]. The 2 populations that have, on the average, the lowest and the highest daily sodium excretion are Romania (163 \pm 86 (SD) mmol/day) and Poland (245 $\pm 88 \mathrm{mmol} /$ day). In spite of this relatively large difference, the daily urine volume is exactly the same $(1.44 \pm 0.51$ and $1.43 \pm 0.52 \mathrm{~L} /$ day, respectively), as is also the daily urinary potassium excretion. Urea excretion is not provided. $\mathrm{U}_{\mathrm{Na}}$, recalculated from $\mathrm{Na}$ excretion and $\mathrm{V}$, is 113 and 171 $\mathrm{mmol} / \mathrm{L}$ in Romania and Poland, respectively.

\section{$\mathrm{U}_{\mathrm{Na}}$ and $\mathrm{V}$ after an Acute Sodium Load}

Most clinical investigations intended to study renal function are usually performed in subjects receiving an initial large water load, followed by the replacement of urinary fluid losses by drinking equivalent amounts of water throughout the study. This procedure is intended to allow easy voiding and to reduce the relative importance of the dead space in the urinary tract. However, the influence that this high hydration may have on the variables under study is ignored (not discussed) in most studies, except for example, in [21]. Choukroun et al. [22] evaluated if this high rate of hydration influences the ability of the kidney to excrete a hypertonic salt load. The same healthy subjects were studied twice on 2 different levels of hydration in a random order. They drank throughout the study either 0.25 or $2.0 \mathrm{~mL}$ water $/ \mathrm{kg}$ body weight every $30 \mathrm{~min}$ (low and high hydration, Low-H and High- $\mathrm{H}$, respectively). After $1 \mathrm{~h}$ equilibration, the subjects received an i.v. infusion of hypertonic $\mathrm{NaCl}(250 \mathrm{~mL}$ of $2 \% \mathrm{NaCl}$ ). Urine was collected $2 \mathrm{~h}$ before and $10 \mathrm{~h}$ after the i.v. $\mathrm{NaCl}$ load. As shown in Figure 4a, sodium excretion rate increased markedly after the load in High-H but the increase was much less in Low-H. Interestingly, potassium excretion rate remained stable and similar in both conditions. During the first $4 \mathrm{~h}$ after the load, urine flow rate increased by $41 \%$ in High-H but decreased by $18 \%$ in Low-H. In contrast, $\mathrm{U}_{\mathrm{Na}}$ almost did not change in High-H but increased from $164 \pm 24$ to $218 \pm 14 \mathrm{mmol} / \mathrm{L}$ $(p<0.001)$ in Low-H [22]. This study shows that an acute sodium load cannot be excreted easily if sodium concentration in the urine cannot increase sufficiently. The excretion of this load is favored by an ample supply of water (above what normal thirst would bring). The delay in sodium excretion on Low-H is reminiscent of the wellknown delay observed before reaching a new sodium balance after an abrupt increase in sodium content of the diet (as illustrated in Fig. 2). 


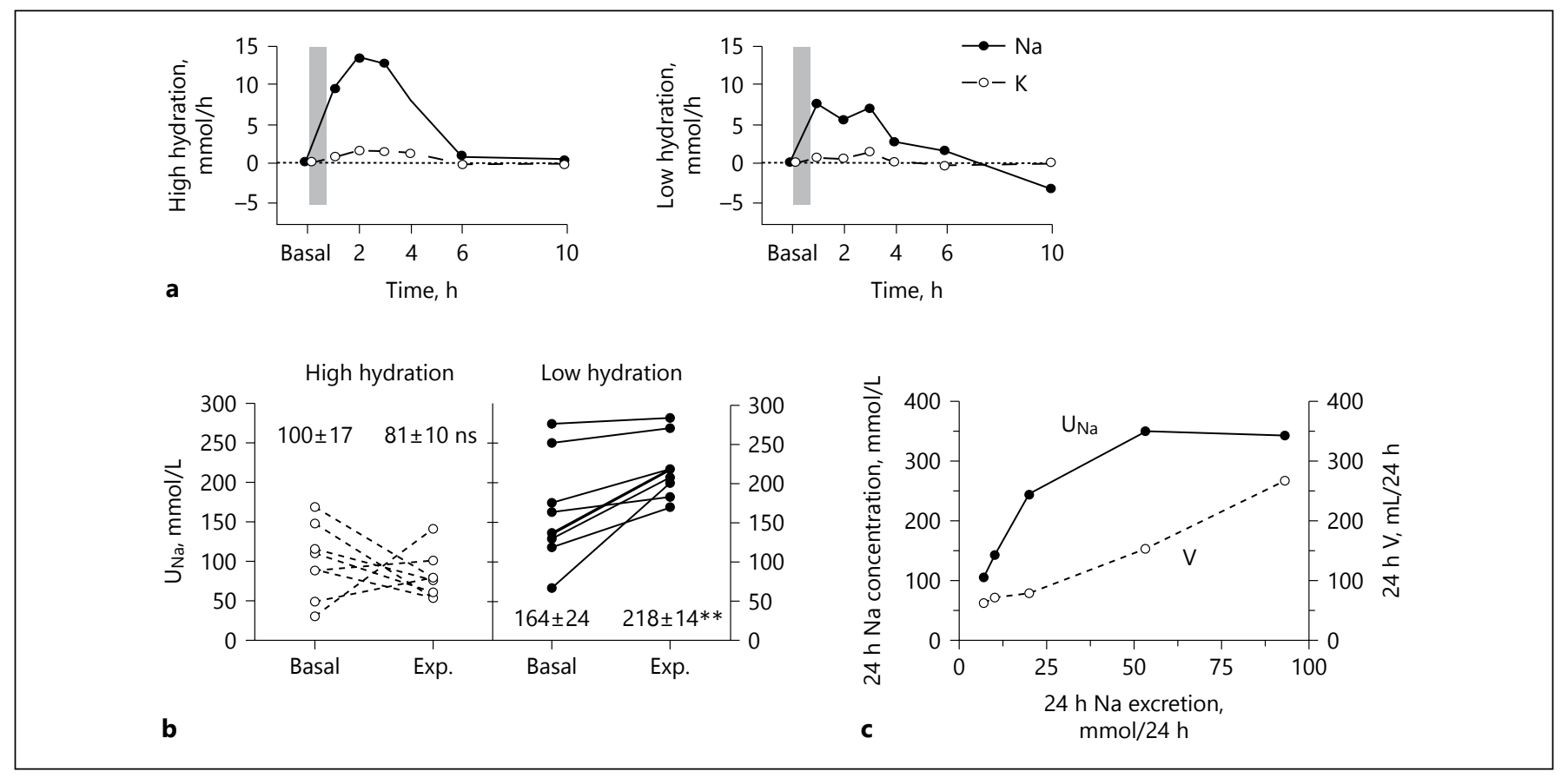

Fig. 4. a Change of 10-h sodium excretion rate in subjects submitted to an acute hypertonic $\mathrm{NaCl}$ load (vertical gray bar) while on a high or a low hydration protocol (described in text). $\mathbf{b}$ Concentration of sodium in urine $\left(\mathrm{U}_{\mathrm{Na}}\right)$ at baseline and $4 \mathrm{~h}$ after the $\mathrm{NaCl}$ load. During the low hydration condition, $\mathrm{U}_{\mathrm{Na}}$ seemed to reach a maximum, as it did not increase further in subjects who already exhibited a high $\mathrm{U}_{\mathrm{Na}}$ during the basal period. Mean \pm SEM are

\section{Why Is It Difficult to Raise Urine Sodium Concentration?}

The difficulty to excrete sodium appears to be due to the limited ability of the kidney to raise $\mathrm{U}_{\mathrm{Na}}$ when $\mathrm{V}$ cannot increase because of the low availability of water. This appears clearly in Figure $4 \mathrm{~b}$. After the load, $\mathrm{U}_{\mathrm{Na}}$ did not increase further in subjects who already exhibited a relatively high $\mathrm{U}_{\mathrm{Na}}$ before the load, and $\mathrm{U}_{\mathrm{Na}}$ did not exceed $280 \mathrm{mmol} / \mathrm{L}$ (i.e., about twice the plasma value) in any subject. An interesting observation is provided by a study performed in minks (Mustela vison) submitted to different salt intakes by adding $0.5,1$, or $2 \% \mathrm{NaCl}$ to their usual diet (already containing $0.5 \% \mathrm{NaCl}$ ) for 4 days at each level [23]. The addition of $0.5 \% \mathrm{NaCl}$ did not modify water intake, whereas the addition of 1 or $2 \%$ salt doubled and almost quadrupled the volume of water consumed, respectively. Figure $4 \mathrm{c}$ shows that the adaptation to progressively increasing sodium intakes initially was achieved almost exclusively by a marked rise in $\mathrm{U}_{\mathrm{Na}}$ (from about 100 to $300 \mathrm{mmol} / \mathrm{L}$ ) without much change in $\mathrm{V}$. With a shown ${ }^{* *} p<0.01$. Reproduced from [22]. c The 24 -h sodium concentration $\left(\mathrm{U}_{\mathrm{Na}}\right)$ and urine flow rate $(\mathrm{V})$ in minks undergoing addition of different percentages of salt to their diet. The adaptation to an increasing need to excrete sodium involved first a rise in $\mathrm{U}_{\mathrm{Na}}$ until this concentration reached a maximum. Then, the adaptation of $24 \mathrm{~h}$ sodium excretion $\left(\mathrm{U}_{\mathrm{Na}} \mathrm{V}\right)$ was mostly achieved by a rise in $\mathrm{V}$. Redrawn after results shown in [23].

further rise in sodium intake, $\mathrm{U}_{\mathrm{Na}}$ reached a plateau and sodium excretion increased mostly as a result of a rise in $\mathrm{V}$. These observations in minks (Fig. 4c) and in humans (Fig. 4b) show that the physiological limit to the ability of the kidney to concentrate sodium is about 2-2.5 times the plasma sodium concentration. In contrast, other solutes like potassium, urea, uric acid, ammonia and so on can be concentrated in the urine 10-1,000-fold above their plasma value (Table 2 in [24]). Note that these solutes exhibit much lower concentrations in plasma than sodium (from 5 to $0.05 \mathrm{mmol} / \mathrm{L}$ vs. $140 \mathrm{mmol} / \mathrm{L}$ for sodium).

The inability to raise $\mathrm{U}_{\mathrm{Na}}$ may be due to the lack of "active" Na secretion along the nephron (i.e., an energy-dependent transepithelial transport against an unfavorable transepithelial concentration difference) and to the integrated action of vasopressin on the kidney. The operation of the urine-concentrating mechanism is largely dependent upon the sodium reabsorption in the thick ascending limb of Henle's loops and in the collecting ducts [25, 26]. Vasopressin secretion is very responsive to small increases in plasma sodium concentration [27]. Thus, the 
infusion of a hypertonic saline load, or a large oral intake of salty food, probably induces an increase in vasopressin secretion that will favor water conservation at the expense of a limited ability to excrete sodium [26]. If the kidney could selectively and rapidly increase $U_{\mathrm{Na}}$, a rapid increase in sodium excretion could be achieved easily without an increase in V. During usual daily activities, after an abrupt change in sodium intake, and without any limitation in water intake, a return to sodium balance requires 2-3 days. This is also explained by the slow rise in $\mathrm{U}_{\mathrm{Na}}$ as shown in Figure 2. Natural selection in all mammals, including humans, probably favored water conservation at the expense of a poorer ability to excrete sodium. As previously discussed [26], this may be explained by the fact that dehydration results in very severe health risks in the short term, while sodium retention may exert adverse consequences (hypertension) only in the long term, and thus, does not prevent individuals to reproduce.

\section{Summary and Conclusions}

This study is exclusively based on a posteriori re-analyses of databases that were previously obtained in diverse protocols. None of these protocols were designed to address the relationships between sodium and water excretion in the face of changes in sodium intake. Thus, the observations reported here bring new, objective information about the respective contribution of $\mathrm{U}_{\mathrm{Na}}$ and $\mathrm{V}$ in the kidney's adaptation to changes in salt intake.

The results presented here clarify the controversial issue regarding the influence of salt intake on the drinking behaviour. It does not challenge the well-established observations that sodium intake stimulates thirst acutely, and that a sudden intake of unusually salty food (or abruptly increasing the salt content of the diet) increases thirst and therefore fluid intake. But the new results presented above show that there is no associated increase in urine volume. The extra fluid ingested remains in the body to limit the rise in plasma sodium concentration by diluting the sodium that cannot be excreted quickly enough. This water retention is responsible for the welldescribed rise in body weight observed after a sudden rise in daily sodium intake (without changes in the intake of other nutrients) and shown here in Figure 5 (top; adapted from the early observations of Earley [28]). As long as the sodium intake remains within a reasonable range (50-250 mmol/day), most of the adaptation rests on changes in the concentration of sodium in the urine without any change in the urine flow rate. If salt intake is increased above a certain threshold (probably 250-300 $\mathrm{mmol} /$ day), the new steady state may possibly require an increase in $\mathrm{V}$ because $\mathrm{U}_{\mathrm{Na}}$ may reach the maximum concentration that the kidney can achieve. After an abrupt increase in salt intake, fluid intake is transiently increased although urine output does not change, and fluid intake returns to previous levels after a few days, as schematized in Figure 5 (bottom).

Even in a steady state condition on their usual sodium diet, some people tend to retain sodium by excessive sodium reabsorption along the nephron. Recent studies show that they excrete an insufficient fraction of their 24-h sodium and water intake during daytime, and compensate this defect by a higher excretion during the night, thus recovering a normal sodium and fluid balance every morning. This nocturnal compensation is achieved at the price of a reduction or lack of the usual blood pressure dipping known to occur during the night [29-32]. The maintenance of a higher blood pressure during the night increases salt and water excretion by the "pressure natriuresis" mechanism, as explained elsewhere [26, 33].

The above results clarify the relationships between sodium and fluid intake and allow to correct some incorrect assumptions based on studies of individuals on an ad libitum diet. In studies reinvestigated here, the changes observed in urine output can obviously not be attributed to one isolated solute, sodium, as subjects who eat more sodium also eat more of other solute-generating food like potassium and proteins. It is thus not valid to conclude that high salt consumption drives higher fluid intake when subjects are on an ad libitum diet. Even when studied in the same subjects with changes exclusively in salt intake, the rise in fluid intake is only transient and disappears once a new steady state is reached. The re-analyses presented in this review also show that urine volume per day is, on the average, about the same in all parts of the world and independent of the level of salt intake.

\section{Acknowledgements}

We are particularly indebted to the following investigators who made available their data and allowed us to use them for the analyses performed in this paper: Michel BURNIER, Service of Nephrology, Department of Medicine, Lausanne University Hospital, and University of Lausanne, Lausanne, Switzerland (Studies A and B); Carmine ZOCCALI, CNR-IFC Institute of Clinical Physiology, Clinical Epidemiology and Pathophysiology of Renal Diseases and Hypertension, Reggio, Calabria, Italy (Study C); Xavier JEUNEMAITRE, INSERM Unit 970, Paris Cardiovascular Research Center-PARCC, Department of Genetics, Hôpital Européen Georges Pompidou, Paris, France (Study D); Aoumeur 
Fig. 5. Schematic representation of the changes occurring after an abrupt increase or decrease in sodium intake. The upper 2 tracings are classical drawings from L. E. Earley [28], subsequently reproduced in a number of textbooks and reviews. The lower 2 panels show how the concentration of sodium in urine $\left(\mathrm{U}_{\mathrm{Na}}\right)$, fluid intake and urine flow rate $(\mathrm{V})$ adapt to the abrupt change in sodium intake. The urine output does not change (dotted line in bottom panel). The extra water drunk in the first few days after the switch to a high salt intake creates a positive fluid balance (shown in grey in bottom panel) that is responsible for the rise in body weight (WT) shown at the top. With an abrupt reduction in sodium intake, the reverse is observed. In both cases, the full return to a new steady state takes a few days. Although fluid intake is altered during a few days, urine output does not change.

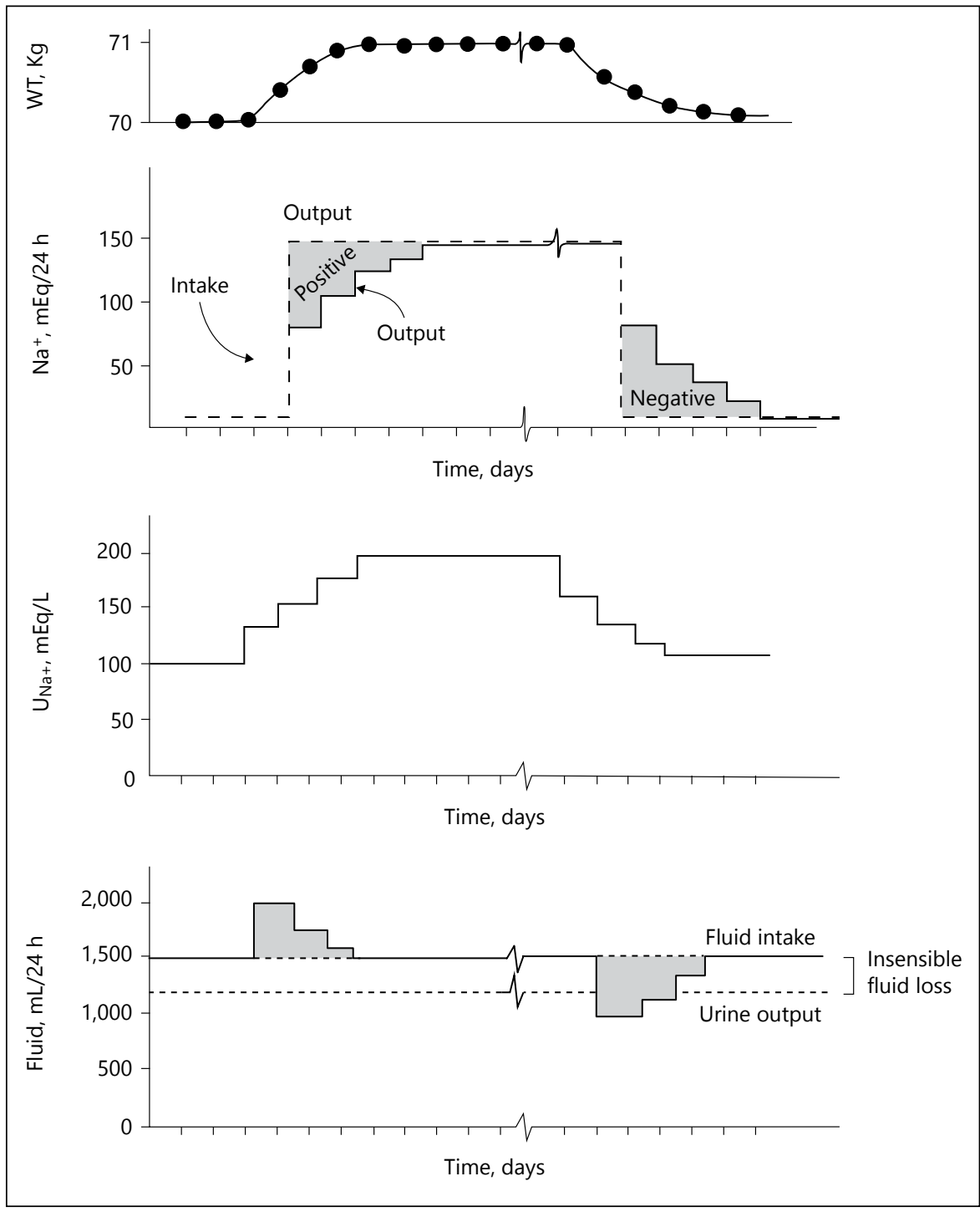

HADJ-AÏSSA, Exploration fonctionnelle rénale, Hospices civils de Lyon, Lyon, France (Study G); Pierre VALEIX, INSERM Unit 557, INRA/CNAM Unit 1125, Université Paris 13, CRNH Ile-deFrance, Bobigny, France (Study H).

\section{Disclosure Statement}

Lise Bankir is an occasional scientific consultant for Danone, France. Other authors have no conflicts of interest to declare.

\section{References}

1 Millard-Stafford M, Wendland DM, O'Dea NK, Norman TL: Thirst and hydration status in everyday life. Nutr Rev 2012;70(suppl 2): S147-S151.

2 Leshem M: Does salt increase thirst? Appetite 2015;85:70-75.

3 Bourque CW, Oliet SH, Richard D: Osmoreceptors, osmoreception, and osmoregulation. Front Neuroendocrinol 1994;15:231274 .
4 Stricker EM, Hoffmann ML: Control of thirst and salt appetite in rats: early inhibition of water and $\mathrm{NaCl}$ ingestion. Appetite 2006;46:234-237.

5 Stanhewicz AE, Kenney WL: Determinants of water and sodium intake and output. Nutr Rev 2015;73(suppl 2):73-82.

6 de Castro JM: The relationship of spontaneous macronutrient and sodium intake with fluid ingestion and thirst in humans. Physiol Behav 1991;49:513-519.
7 Thrasher TN, Brown CJ, Keil LC, Ramsay DJ: Thirst and vasopressin release in the dog: an osmoreceptor or sodium receptor mechanism? Am J Physiol 1980;238:R333R339.

8 Perucca J, Bouby N, Valeix P, Bankir L: Sex difference in urine concentration across differing ages, sodium intake, and level of kidney disease. Am J Physiol Regul Integr Comp Physiol 2007;292:R700-R705. 
9 Zoccali C, Mallamaci F, Leonardis D: Assessment of the salt-arterial pressure relationship in mild hypertensive subjects by 24 -hour ambulatory monitoring. Clin Sci (Lond) 1994;87: 635-639.

10 Chiolero A, Maillard M, Nussberger J, Brunner HR, Burnier M: Proximal sodium reabsorption: an independent determinant of blood pressure response to salt. Hypertension 2000;36:631-637.

11 Giacche M, Vuagnat A, Hunt SC, Hopkins PN, Fisher ND, Azizi M, Corvol P, Williams $\mathrm{GH}$, Jeunemaitre X: Aldosterone stimulation by angiotensin II: influence of gender, plasma renin, and familial resemblance. Hypertension 2000;35:710-716.

12 Sacks FM, Svetkey LP, Vollmer WM, Appel LJ, Bray GA, Harsha D, Obarzanek E, Conlin PR, Miller ER 3rd, Simons-Morton DG, Karanja N, Lin PH: Effects on blood pressure of reduced dietary sodium and the Dietary Approaches to Stop Hypertension (DASH) diet. DASH-Sodium Collaborative Research Group. N Engl J Med 2001;344:3-10.

13 Luft FC, Fineberg NS, Sloan RS, Hunt JN: The effect of dietary sodium and protein on urine volume and water intake. J Lab Clin Med 1983;101:605-610.

14 Ogna A, Forni Ogna V, Bochud M, Guessous I, Paccaud F, Burnier M, Wuerzner G: Association between obesity and glomerular hyperfiltration: the confounding effect of smoking and sodium and protein intakes. Eur J Nutr 2016;55:1089-1097.

15 Damgaard M, Norsk P, Gustafsson F, Kanters JK, Christensen NJ, Bie P, Friberg L, Gadsboll $\mathrm{N}$ : Hemodynamic and neuroendocrine responses to changes in sodium intake in compensated heart failure. Am J Physiol Regul Integr Comp Physiol 2006;290:R1294-R1301.

16 Damgaard M, Gabrielsen A, Heer M, Warberg J, Bie P, Christensen NJ, Norsk P: Effects of sodium intake on cardiovascular variables in humans during posture changes and am- bulatory conditions. Am J Physiol Regul Integr Comp Physiol 2002;283:R1404-R1411.

17 He FJ, Markandu ND, Sagnella GA, MacGregor GA: Effect of salt intake on renal excretion of water in humans. Hypertension 2001;38:317-320

18 Hercberg S, Galan P, Preziosi P, Bertrais S, Mennen L, Malvy D, Roussel AM, Favier A, Briancon S: The SU.VI.MAX Study: a randomized, placebo-controlled trial of the health effects of antioxidant vitamins and minerals. Arch Intern Med 2004;164:23352342.

19 Intersalt: an international study of electrolyte excretion and blood pressure. Results for 24 hour urinary sodium and potassium excretion. Intersalt Cooperative Research Group. BMJ 1988;297:319-328.

20 Stolarz K, Staessen JA, Kawecka-Jaszcz K, Brand E, Bianchi G, Kuznetsova T, Tikhonoff V, Thijs L, Reineke T, Babeanu S, Casiglia E, Fagard R, Filipovsky J, Peleska J, Nikitin Y, Struijker-Boudier H, Grodzicki T: Genetic variation in CYP11B2 and AT1R influences heart rate variability conditional on sodium excretion. Hypertension 2004;44:156-162.

21 Burnier M, Monod ML, Chiolero A, Maillard M, Nussberger J, Brunner HR: Renal sodium handling in acute and chronic salt loading/ depletion protocols: the confounding influence of acute water loading. J Hypertens 2000; 18:1657-1664.

22 Choukroun G, Schmitt F, Martinez F, Drueke TB, Bankir L: Low urine flow reduces the capacity to excrete a sodium load in humans. Am J Physiol 1997;273(5 pt 2):R1726-R1733.

23 Eriksson L, Valtonen M, Mäkelä J: Water and electrolyte balance in male mink (Mustela vison) on varying dietary $\mathrm{NaCl}$ intake. Acta Physiol Scand Suppl 1984;537:59-64.

24 Bankir L, Bouby N, Ritz E: Vasopressin: a novel target for the prevention and retardation of kidney disease? Nat Rev Nephrol 2013; 9:223-239.
25 Bankir L, Fernandes S, Bardoux P, Bouby N, Bichet DG: Vasopressin-V2 receptor stimulation reduces sodium excretion in healthy humans. J Am Soc Nephrol 2005;16:1920-1928.

26 Bankir L, Bichet DG, Bouby N: Vasopressin $\mathrm{V} 2$ receptors, $\mathrm{ENaC}$, and sodium reabsorption: a risk factor for hypertension? Am J Physiol Renal Physiol 2010;299:F917-F928.

27 Zerbe RL, Robertson GL: Osmoregulation of thirst and vasopressin secretion in human subjects: effect of various solutes. Am J Physiol 1983;244:E607-E614.

28 Earley LE: Sodium metabolism; in Maxwell HM, Kleeman CR (eds): Clinical disorders of fluid and electrolyte metabolism. New York: McGraw-Hill, 1972, pp 95-119.

29 Fujii T, Uzu T, Nishimura M, Takeji M, Kuroda $S$, Nakamura $S$, Inenaga T, Kimura G: Circadian rhythm of natriuresis is disturbed in nondipper type of essential hypertension. Am J Kidney Dis 1999;33:29-35.

30 Bankir L, Bardoux P, Mayaudon H, Dupuy O, Bauduceau B: [Impaired urinary flow rate during the day: a new factor possibly involved in hypertension and in the lack of nocturnal dipping]. Arch Mal Coeur Vaiss 2002;95:751754

31 Bankir L, Bochud M, Maillard M, Bovet P, Gabriel A, Burnier M: Nighttime blood pressure and nocturnal dipping are associated with daytime urinary sodium excretion in African subjects. Hypertension 2008;51:891898

32 Guerrot D, Hansel B, Perucca J, Roussel R, Bouby N, Girerd X, Bankir L: Reduced insulin secretion and nocturnal dipping of blood pressure are associated with a disturbed circadian pattern of urine excretion in metabolic syndrome. J Clin Endocrinol Metab 2011;96: E929-E933.

33 Burnier M, Coltamai L, Maillard M, Bochud M: Renal sodium handling and nighttime blood pressure. Semin Nephrol 2007;27:565571. 